\title{
Deformation of Mitochondrial Cristae in Human Neural Progenitor Cells Exposed to Valproic Acid
}

\author{
RODRIGO M. DA COSTA ${ }^{1}$, KARINA KARMIRIAN ${ }^{1}$ and STEVENS K. REHEN ${ }^{1,2}$ \\ ${ }^{1}$ Instituto D’Or de Pesquisa e Ensino/ IDOR, Rua Diniz Cordeiro, 30, Botafogo, 22281-100 Rio de Janeiro, RJ, Brazil \\ ${ }^{2}$ Instituto de Ciências Biomédicas, Universidade Federal do Rio de Janeiro, Av. Carlos Chagas, 373, bloco K, $2^{\circ}$ andar, \\ sala 35, Centro de Ciências da Saúde, Cidade Universitária, Ilha do Fundão, 21941-902 Rio de Janeiro, RJ, Brazil
}

Manuscript received on October 5, 2017; accepted for publication on December 4, 2017

\begin{abstract}
Neural development represents a dynamic process where mitochondrial integrity is decisive for neuronal activity. Structural changes in these organelles may be related to neurological disorders. Valproic acid (VPA) is an anticonvulsive drug commonly used for epilepsy treatment and its use is associated to increased risk of neuropsychiatric disorders. Recently we showed changes in shape and membrane potential in mitochondria from human neural progenitor cells (NPCs) exposed to VPA (da Costa et al. 2015). Here, we applied transmission electron microscopy and electron tomography to evaluate mitochondrial damage caused by VPA in NPCs. Results showed mitochondrial cristae disorganization in a dose dependent manner. Disturbance in mitochondrial ultrastructure may influence metabolism, leading to synaptic plasticity and neurogenesis impairment. These data contribute to understanding VPA exposure potential effects on brain development.
\end{abstract}

Key words: transmission electron microscopy, mitochondria, valproic acid, epilepsy, human neural progenitor cells, electron tomography.

\section{INTRODUCTION}

Mitochondria are organelles that contribute significantly to proper development of central nervous system. Neuronal differentiation and health depend on the functional integrity of mitochondria due to high level of cellular energy required (Levytskyy et al. 2016, Li et al. 2004, Robicsek et al. 2013). Mitochondrial dysfunction, on the other hand, affects neuronal metabolism as

Correspondence to: Stevens Kastrup Rehen

E-mail: srehen@lance-ufrj.org

* Contribution to the centenary of the Brazilian Academy of Sciences. well as axonal transport, neurotransmitter release and synaptic plasticity (Jurata et al. 2006, Park et al. 2010, Rossignol and Frye 2012). Furthermore, mitochondrial dysfunction is commonly associated to neuropsychiatric disorders due to defects in neurotransmitter release and cell redox signaling (Arun et al. 2016, Tait and Green 2012). In addition, ultrastructural analysis of rats' hippocampus in pentylenetetrazol (PTZ)-induced status epilepticus showed alterations in mitochondrial morphology, suggesting a dysfunction related to epileptic pathophysiology (Zhvania et al. 2015). 
In 1882, valproic acid (VPA) was first described as an organic solvent. It was approved for epilepsy treatment in France in 1967 and since 1978 it has been used in the United States of America. It is one of the main drugs for epilepsy treatment. Its therapeutic potential was serendipitously discovered in 1962 after being used as a solvent for experimental anticonvulsants (Lagace et al. 2004). VPA is one of the main drugs used for more than 30 years for epilepsy treatment. Clinical benefits have already been proved, such as decrease of recurrent seizures, mood stabilization and control of absence epilepsy crises (Chateauvieux et al. 2010). However, the use of this anticonvulsive drug specifically in the first trimester of pregnancy is strongly associated to an increased risk of congenital malformations like spina bifida (Jentink et al. 2010, Mawhinney et al. 2012). Indeed, it has been shown that antiepileptic drugs (AED), such as VPA, present some of the most well known mitochondrion-toxic side effects, including hepatotoxicity, hyperammonemic encephalopathy, hypersensitivity reactions, weight gain, pancreatitis, hematological abnormalities, gastrointestinal disturbances, neurological toxicity, as well as renal injury (Nanau and Neuman 2013). Those could be some of the causes of behavioral and cognitive impairment observed in patients treated with AEDs during childhood or whose mothers were treated during pregnancy (Sui and Chen 2012, Yochum et al. 2008). The influence of drugs used worldwide in mitochondrial function is a key point to understand real benefits and patient's safety after long-term exposures.

Increased risk of major congenital malformations and other birth defects, developmental delay in 30 to $40 \%$ of pre-school children, risk of autism and attention deficit hyperactivity disorder, reduced cognitive and motor abilities, memory problems, complications with language and speech and reduced intellectual performance in the infants associated to maternal VPA treatment during pregnancy raised the most concerns (Bromley et al. 2008,
Christensen et al. 2013, Cohen et al. 2011, Cummings et al. 2011, Meador et al. 2013, 2009a, b, 2008, Roullet et al. 2013, Thomas et al. 2008, Wide et al. 2007). In patients diagnosed with mitochondrial disorders, VPA treatment demonstrated few side-effects such as severe liver failure and cortical blindness (Castro-Gago et al. 1999), chronic progressive external ophtalmoplegia (CPEO) (Krähenbühl et al. 2000), aggravated epilepsy symptoms and induced convulsions in patients with mitochondrial encephalopathy lactic acidosis and stroke-like episodes (MELAS) (Lin and Thajeb 2007) and induced liver failure in patients with mitochondria recessive ataxia syndrome (MIRAS) (Hakonen et al. 2010).

Recent papers showed drug-induced mitochondrial changes in pyramidal neurons after exposure to VPA in rodents (Sendrowski et al. 2013). VPA also induced mitochondrial respiratory chain complexes I and IV inhibition in pigs and loss of cytochrome-c oxidase with simultaneous reduction cytochrome aa3 in rats (Ponchaut et al. 1992). Mitochondrial morphology was also affected in rats after VPA administration. Conformational changes of respiratory chain proteins and structural abnormalities of the inner mitochondrial membrane were described (Rumbach et al. 1986). In vitro, it was observed that VPA decreases $\mathrm{O} 2$ and mitochondrial membrane potential rates, increases reactive oxygen species (ROS) levels, depletes ATP levels, increases cell death and decreases superoxide dismutase in HepG2 cells (Komulainen et al. 2015). It was also described that VPA can increase pro-apoptotic activity of the mitochondrial membrane by stabilizing a specific acetyl modification of the p53 tumor suppressor protein (Chen et al. 2011). On the other hand, VPA, associated with lithium, protected SH-SY5Y cells against oxidative stress-induced cell death (Lai et al. 2006) and against methamphetamine-induced reduction of cytochrome-c activity besides other beneficial effects (Bachmann et al. 2009). However, 
a major challenge is to analyze VPA effects in human fetal-like neural cells and its influence in organelles morphology and function. The use of human stem cell-derived neural cells is an alternative model to better understand cell biology and embryonic environment in neurological diseases (Lopes and Rego 2016, Mertens et al. 2016, Prajumwongs et al. 2016).

Previous work from our group showed, by high content microscopy analysis, that VPA disturbs mitochondrial morphology and alters mitochondrial membrane potential (MMP) in neural progenitor cells derived from human embryonic stem cells after 24h (da Costa et al. 2015). Despite the clear morphological alterations observed after VPA treatment, information regarding fine mitochondrial morphology was missing.

To address this issue, we applied electron microscopy and electron tomography to investigate whether VPA disturbs mitochondria ultrastructure in human neural progenitor cells (NPCs). Here we described ultrastructural changes in mitochondria after exposure to VPA, such as cristae disorganization, which are believed to be one of the cellular mechanisms of neuropsychiatric disorders.

\section{MATERIALS AND METHODS}

\section{NEURAL PROGENITOR CELLS}

Neural progenitor cells were obtained from human embryonic stem cells (hESCs) (Fraga et al. 2011). Briefly, hESCs were grown at $5 \% \mathrm{CO} 2$ and $37^{\circ} \mathrm{C}$ on Matrigel (BD Biosciences) coated $100 \mathrm{~mm}$ plates in hESC medium consisting of high-glucose Dubelcco's modified Eagle's medium (DMEM/ F12) supplemented with $2 \mathrm{mM}$ l-glutamine, $20 \%$ knockout serum replacement, $110 \mathrm{uM}$ 2-mercaptoethanol, 1\% nonessential amino acids and $8 \mathrm{ng} / \mathrm{ml}$ basic Fibroblast Growth Factor (bFGF) (all reagents from Life Technologies). Confluent hESC cultures were dissociated from culture plates using Accutase (Thermo Fisher Scientific,
MA, USA) for $15 \mathrm{~min}$ at $37^{\circ} \mathrm{C}$, harvested in fresh hESC medium, washed twice in fresh medium and ressuspended in hESC medium containing $10 \mathrm{uM}$ ROCK inhibitor (Y-27632, Millipore, MA, USA) and plated on Matrigel coated plates at $18 \times 10^{3}$ cells $/ \mathrm{cm}^{2}$. hESC medium was replaced daily until cultures were $80 \%$ confluent then replaced by a FGF-free version of hESC medium supplemented with $10 \mathrm{uM} \mathrm{SB} 431542$ and $500 \mathrm{ng} / \mathrm{ml}$ Noggin. The medium was replaced every two days for eleven days. Cells were then removed from the plates using Accutase, resuspended in NPC medium consisting of DMEM/F12 supplemented with $1 \mathrm{x}$ B27, 1 x N2, 20 ng/ml FGF and 20 ng/ml Epidermal Growth Factor (EGF) and plated on $10 \mathrm{ug} / \mathrm{ml}$ polyornithine (Sigma, MO, USA) $2.5 \mathrm{ug} / \mathrm{ml}$ laminin (Invitrogen, CA, USA) coated plates. NPC medium was replaced every two days.

\section{TRANSMISSION ELECTRON MICROSCOPY}

NPCs were plated on $60 \mathrm{~mm}$ plates previously coated with poly-ornithine and laminin and treated with $0.01,0.1$ and $1 \mathrm{mM} \mathrm{VPA}$. After 24 hours, cells were detached from each plate using Accutase for 5 min at $37^{\circ} \mathrm{C}$ and fixed in $2.5 \%$ glutaraldehyde solution diluted in $0.1 \mathrm{M}$ cacodylate buffer (v/v). Cells were then post-fixed for $5 \mathrm{~min}$ in $1 \% \mathrm{OsO}_{4}$ solution in cacodylate buffer containing $5 \mathrm{mM} \mathrm{CaCl}_{2}$ and $0.8 \%$ potassium ferricyanide. Samples were dehydrated in increasing acetone concentration solutions and embedded in epoxy resin (EMS, PA, USA). Ultra-thin $(70 \mathrm{~nm})$ sections were stained with uranyl acetate and lead citrate and observed with a Leo 900 electron microscope at $80 \mathrm{kV}$ (Zeiss, Germany).

\section{MITOCHONDRIA QUANTIFICATION}

Electron microscopy images were acquired at $15,000 \mathrm{x}$ magnification for mitochondria quantification. From each condition, twenty photographs were randomly taken and one hundred 
mitochondria were counted and distributed in two groups: "Normal" and "Altered". "Normal" mitochondria presented organized and parallel distribution of cristae. Crista orientation had to be perpendicular to mitochondria's profile longer axis. Mitochondria that could not match these criteria were placed in the "Altered" group. Results were expressed as the percentage of "Normal" and "Altered" mitochondria in each condition.

\section{ELECTRON TOMOGRAPHY AND 3D-MODELING}

Semi-thin sections $(200 \mathrm{~nm})$ from electron microscopy samples embedded in epoxy resin (as described above) were collected on 200 mesh $\mathrm{Ni}$ grids, post stained with uranyl acetate and lead citrate and incubated in $10 \mathrm{~nm}$ gold colloid solution on both sides for $5 \mathrm{~min}$ and washed in distilled water. A $200 \mathrm{kV}$ transmission electron microscope (Tecnai G2, FEI Company, OR, USA) equipped with a $4 \mathrm{k} \times 4 \mathrm{k}$ CCD camera (Eagle, FEI Company, OR, USA) was used to acquire the tomograms. Tilt series from $-65^{\circ}$ to $+65^{\circ}$ with angular increment of $1^{\circ}$ was used for single-axis tomography. Automated data acquisition in the tilt series was conducted using Xplore 3D (FEI Company, OR, USA). Alignments were applied using fiducial markers and weighted back projections with the IMOD software package (University of Colorado, USA). Single-tilt tomograms were analyzed and modeled using the IMOD software package (University of Colorado, USA). Features of interest were manually contoured in serial optical slices extracted from the tomograms. Mitochondrial cristae were categorized as normal when presenting parallel adjacent membranes. Altered mitochondria were categorized when presenting small segmented cristae, with round morphology or dilated. A total of 162 cristae were manually counted in three reconstructed mitochondria from both control and VPA treated cells.

\section{STATISTICAL ANALYSIS}

Data were analyzed by one-way analysis of variance (ANOVA) and are expressed as mean \pm standard deviation from at least three independent experiments. Values of $p<0.05$ were considered statistically significant. All analyses were performed using GraphPad Prism 6.07 (GraphPad Software).

\section{RESULTS}

We performed transmission electron microscopy in NPCs treated with VPA in order to evaluate possible ultrastructural changes in mitochondria, especially in cristae. Our results revealed that naive NPCs presented highly organized mitochondrial cristae with regular thickness and electron density (Figure 1a). These characteristics were also present after exposure to $0.01 \mathrm{mM}$ VPA (Figure 1b) but in the presence of higher concentrations (0.1 $\mathrm{mM}$ and $1 \mathrm{mM}$ VPA), asymmetrical distribution and fragmentation of cristae and enlargement of mitochondrial matrix were observed (Figure 1c and d).

Individually, mitochondria presented obvious structural deformations in the presence of VPA compared to control; however, it is possible to find either normal or altered mitochondria in all four conditions addressed in this work. To evaluate VPA effects on the number of damaged mitochondria, we grouped mitochondria into two distinct bins ("normal" and "altered") based on cristae organization and morphology (Figure 2a). We counted all mitochondria present in twenty randomly selected electron microscopy images in each condition with the same magnification $(7.000 x)$. Figure $2 b$ shows an integer control mitochondrion with homogeneous distribution of parallel cristae (Figure 2b'). In contrast, Figure $2 \mathrm{c}$ shows a damaged mitochondrion with heterogeneous distribution of swollen cristae and loss of membrane contacts between inner and 
outer membranes (Figure 2c'). Three independent experiments showed that control cells contain $8 \%$ of altered mitochondria, whereas $0.01 \mathrm{mM}, 0.1 \mathrm{mM}$ and $1 \mathrm{mM}$ VPA treatment significantly increased this percentage to $58 \%, 69 \%$ and $87 \%$ respectively (Figures 2d-g).

In order to evaluate the inner mitochondrial architecture, we submitted the EM preparations to electron tomography and 3D modeling. Control cells displayed symmetric and homogeneous cristae (Figures $3 \mathrm{a}$ and $\mathrm{b}$ ) with crista segmentation (Figure $3 \mathrm{c})$ and small tubular crista almost inexistent (Figure 3d). Cells exposed to 1mM VPA showed 29.4\% more dilated mitochondria cristae (Figure $3 \mathrm{f}$ ) and $15.7 \%$ more small fragmented cristae (Figures $3 \mathrm{~g}$ and $\mathrm{h}$ ) than control (Figures $3 \mathrm{c}$ and $\mathrm{d}$ ). Absolute number of mitochondria cristae is shown in Table I.

Together these data show that mitochondria internal architecture is highly sensitive to VPA in a dose dependent manner despite the fact that a small fraction of these organelles do not present any effect.

\section{DISCUSSION}

Development and renewing of central nervous system are continuous processes in which neurons and glial cells are constantly differentiating, maturating and integrating, even postnatally (Gage 2000, Lee 2012). The complexity involved in such processes is of equal value of its sensitivity to intrinsic and extrinsic factors, making it vulnerable to errors and thus, prone to undesired outcomes. In the present work, we described the effects of VPA, a widely prescribed anticonvulsant drug, in NPCs derived from human ESCs. We showed that low concentrations of this drug are capable of disturbing mitochondrial cristae ultrastructure.

Mitochondrial morphology is undoubtedly the most dramatic alteration induced by VPA in this study. We did not observe any cell morphology alteration (data not shown). Loss of mitochondria integrity in NPCs may lead to impaired $\mathrm{Ca}^{++}$ regulation and redox signaling, compromising synaptic development and plasticity and determination of cell survival or death ( $\mathrm{Li}$ et al. 2004, Mattson et al. 2008).

TABLE I

Absolute number of mitochondrial cristae from control cells and $1 \mathrm{mM} \mathrm{VPA}$ treated cells.

\begin{tabular}{cccc}
\hline & $\begin{array}{c}\text { Total } \\
\text { Cristae }\end{array}$ & $\begin{array}{c}\text { Dilated } \\
\text { Cristae }\end{array}$ & $\begin{array}{c}\text { Small } \\
\text { Fragmented } \\
\text { Cristae }\end{array}$ \\
\hline Control & 88 & 12 & 32 \\
$1 \mathrm{mM} \mathrm{VPA}$ & 74 & 17 & 38 \\
\hline
\end{tabular}
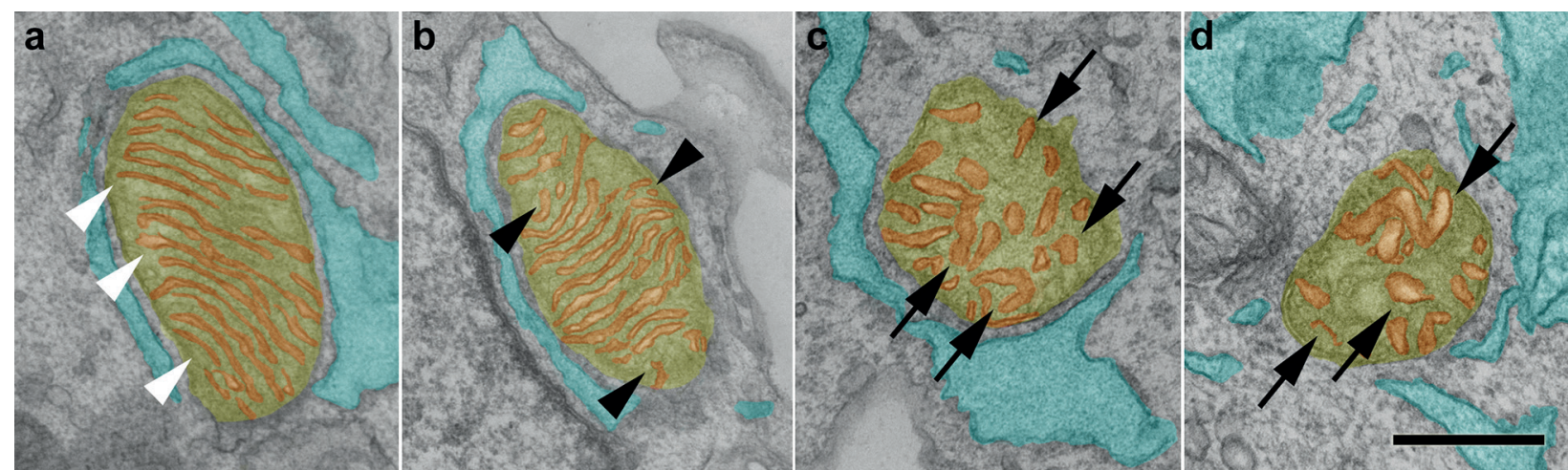

Figure 1 - Mitochondrial cristae are affected after VPA treatment. (a) Transmission electron microscopy showed that control cells presented regular distribution of thin and parallel oriented cristae in mitochondria (white arrowheads). Mild alterations were seen after $0.01 \mathrm{mM}$ VPA treatment (b) (black arrowheads) and high degree of cristae disorganization and swelling after 0.1 and $1 \mathrm{mM}$ VPA treatment (c and d) (arrows). Endoplasmic reticulum was also seen in close contact with mitochondria in all conditions (ER). Inter membrane space: yellow; cristae: orange and endoplasmic reticulum: blue. Bar $=1 \mu \mathrm{m}$. 

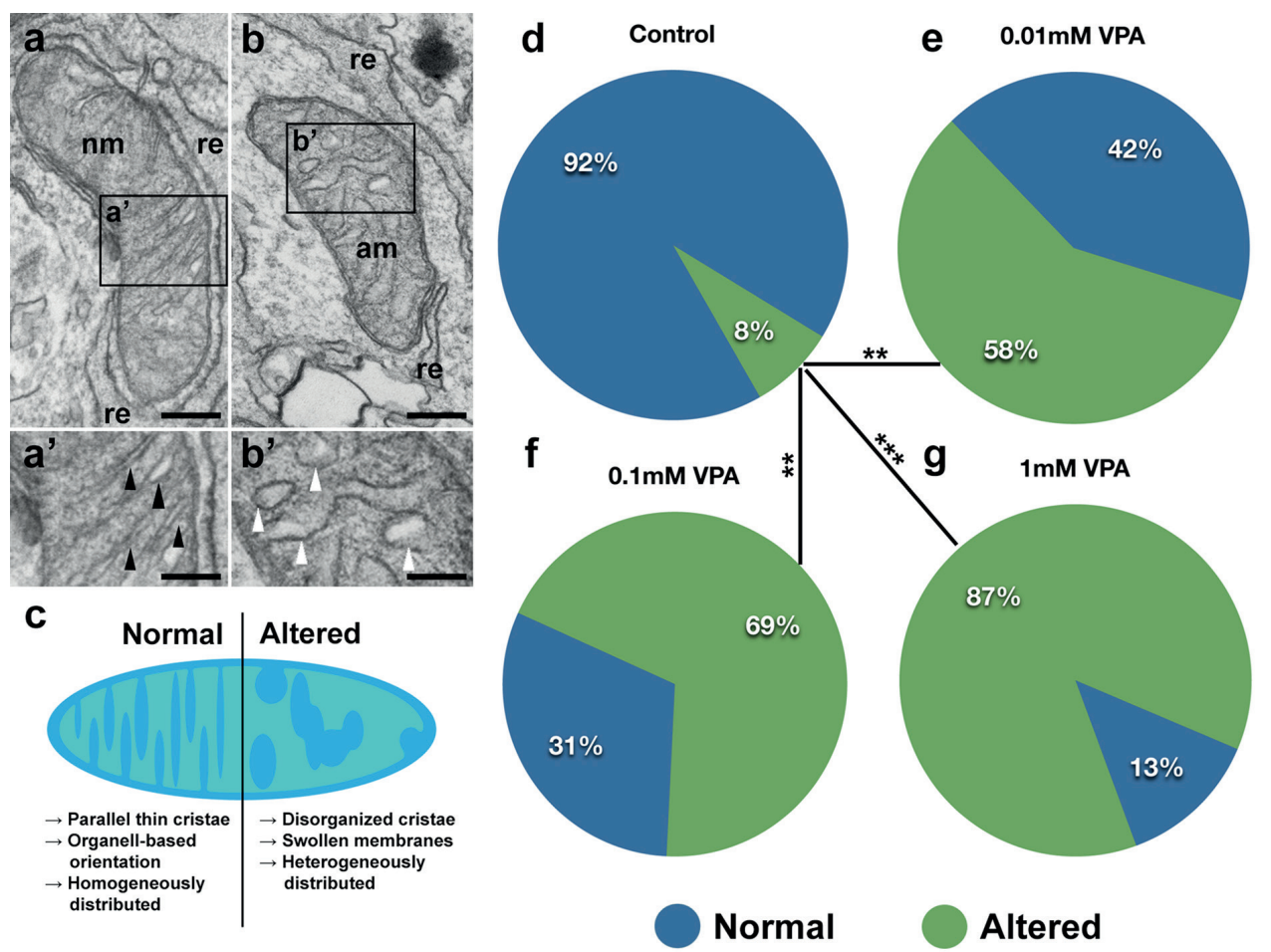

Figure 2 - VPA increases the number of altered mitochondria. Normal mitochondria (nm) presented regular distribution of cristae (a and a') (black arrowheads) whereas altered mitochondria (am) presented disorganized and heterogeneous distribution of cristae (b and b') (white arrowheads). Endoplasmic reticulum (er) was observed in close contact with mitochondria in all conditions. Graphic representation of mitochondria depicts morphological features used in classification (c). Control cells presented $8 \% \pm 2 \%$ of altered mitochondria (d). VPA treatment showed significant increase in $0.01 \mathrm{mM}$ $(58 \% \pm 3 \%)(\mathbf{e}), 0.1 \mathrm{mM}(69 \% \pm 11 \%)(\mathbf{f})$ and $1 \mathrm{mM}(87 \% \pm 8 \%)(\mathbf{g})$ concentrations. Bar in $\mathbf{a}$ and $\mathbf{b}=$ $500 \mathrm{~nm}$; bar in $\mathbf{a}^{\prime}$ and $\mathbf{b}^{\prime}=250 \mathrm{~nm}$. ${ }^{* *} p<0.01$ and $* * * p<0.001$.

Cristae structure is highly dependent on intracellular $\mathrm{Ca}^{++}$concentrations and specific proteins responsible for anchoring the crista junctions domains to the outer mitochondrial membrane (Bohnert et al. 2012, Zerbes et al. 2012). Disturbances in mitochondria membrane homeostasis may lead to loss of important protein interactions, which are thought to, among other things, play a significant role in the processes of neurodevelopment, including neurite outgrowth, neuronal migration, neurogenesis, intra-cellular cAMP signaling (Duan et al. 2007, Kamiya et al. 2005, Mao et al. 2009). It also promotes a clear cellular basis for schizophrenia (Park et al. 2010).

The effects of VPA here described are not seen in all mitochondria. This is due to the high mitochondrial heterogeneity observed not only across tissues but also within the same cell. It becomes even more complex in the case of induced pluripotentstem cells, because of their differentiation stage and reprogramming methodologies, which can alter the composition of external and internal membranes, intracellular $\mathrm{Ca}++$ regulation, oxygen sensing and ROS generation (Woods 2017).

Besides, VPA and its metabolites inhibit mitochondrial pyruvate uptake, thus compromising energy production in inverted submitochondrial vesicles prepared from rat liver (Aires et al. 2008, Silva et al. 2008), impairs structural organization of inner mitochondrial membrane (Rumbach et al. 1986), causes neuronal damage and social deficits, such as cognitive, motor, emotional and social 


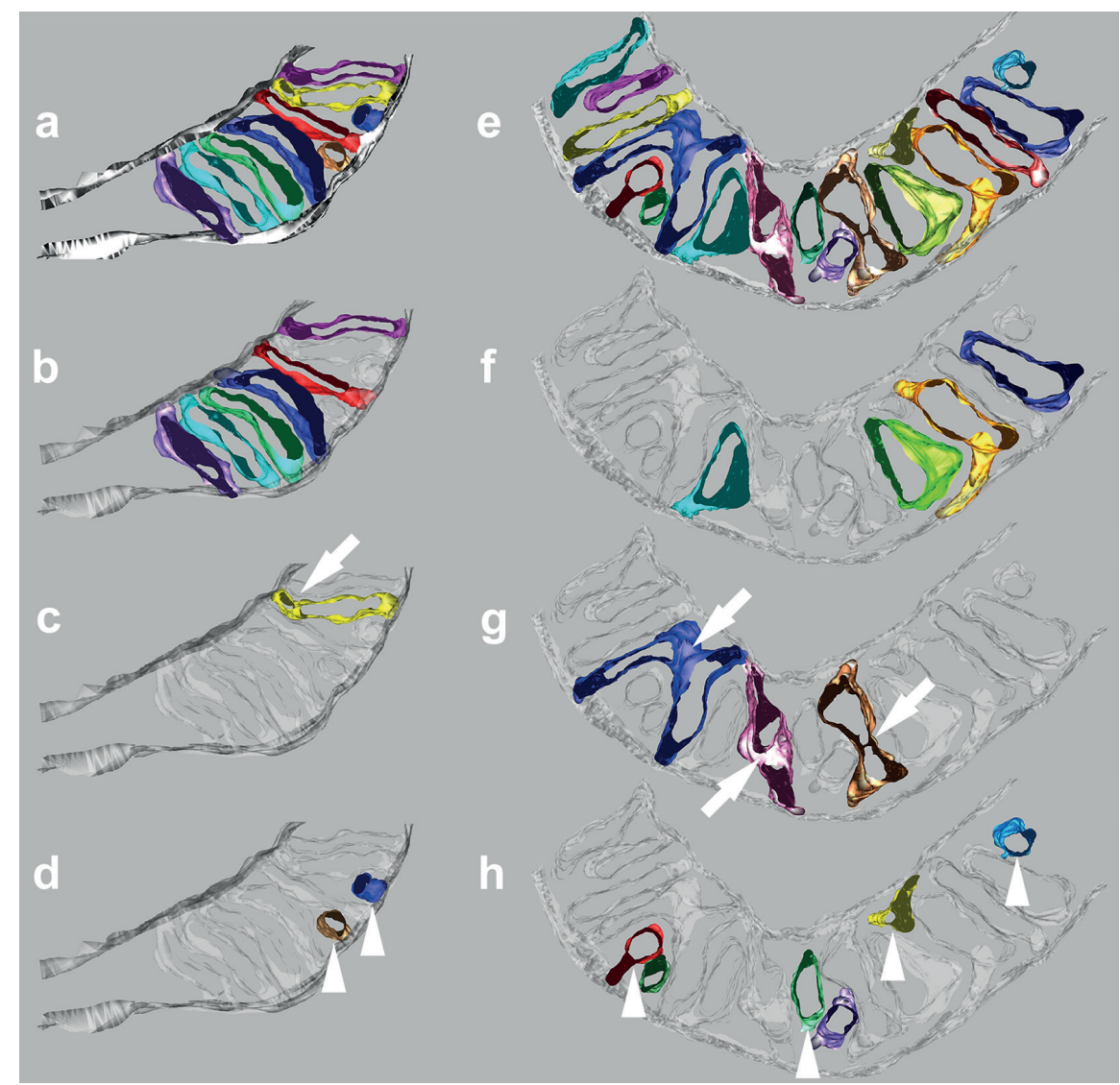

Figure 3 - Mitochondrial cristae alterations induced by VPA. Representative 3-D modeling of mitochondria showed parallel and symmetrical cristae in control cells (a-c) with rare small-detached cristae (d) (arrowheads), whereas VPA induced morphological alterations such as distensions (f), increased number of interconnections (g) (arrows) and smalldetached cristae (h) (arrowheads).

skills delayed maturation in neonatal mice, as well as enhanced synaptic plasticity in the medial prefrontal cortex and enhanced fear memory in rat model, which might contribute to some symptoms of autism (Sui and Chen 2012, Yochum et al. 2008). Moreover, Sgobio et al. (2010) showed that VPA induces dendritic spine abnormalities and impairment in specific hippocampal-dependent memory task. More precisely, damages to mitochondria internal membrane are expected to influence mitochondrial bioenergetics processes in vivo (Mannella et al. 2013), which might, in turn, lead to a disruption of normal neural plasticity and promote the development or progression of psychiatric disorders (Manji et al. 2012). The effects of VPA observed in our work, consistently add missing pieces by which this drug acts in NPCs and supports many reports found in the literature.

One major limitation to study VPA effects in human mitochondria is the availability of a proper model. Experiments using neuroblastoma cells presents neuroprotective effects of VPA through inhibition of mitochondrial apoptotic pathway (Zhang et al. 2017). Another group showed protective effect against migraine in SH-SY5Y cells by modulating mitochondrial biogenesis and function (Li et al. 2016). On the other hand, VPA inhibits mitochondrial respiration and leads to mitochondrial dysfunction in HepG2 cells (Komulainen et al. 2015). The disparity found in 
literature raise the concern of using high resolution imaging methods coupled to proper models and controls in order to understand the cell biology of complex disorders affecting human central nervous system development and the effects of a growing number of drugs and bioactive molecules. Controversial data regarding VPA effects are published elsewhere (Abematsu et al. 2010, Aires et al. 2008, Bachmann et al. 2009, Finsterer and Zarrouk Mahjoub 2012, Meador et al. 2009a, b, Qing et al. 2008, Roullet et al. 2013, Rumbach et al. 1986, Silva et al. 2008, Sui and Chen 2012, Wide et al. 2007, Yochum et al. 2008). The use of human NPCs in vitro is a major breakthrough in approaching responses that are more precise in cell-specific targeting, pharmacological responses and ultrastructure.

Based on our results, we propose that VPA induces mitochondria cristae deformation in human neural progenitor cells. These data suggest morphological disruption in mitochondria caused by VPA may impair metabolism and neural development if incorporated into a long-term therapeutic approach in children.

\section{ACKNOWLEDGMENTS}

We thank Centro Nacional de Biologia Estrutural e Bioimagem (CENABIO) and Laboratório de Ultraestrutura Celular Hertha Meyer for electron microscopy and tomography assistance. This work was supported by Fundação Carlos Chagas Filho de Amparo à Pesquisa do Estado do Rio de Janeiro (FAPERJ), Conselho Nacional de Desenvolvimento Científico e Tecnológico (CNPq), Coordenação de Aperfeiçoamento de Pessoal de Nível Superior (CAPES), Banco Nacional de Desenvolvimento (BNDES) and Financiadora de Estudos e Projetos (Finep).

\section{REFERENCES}

ABEMATSU M, TSUJIMURA K, YAMANO M, SAITO M, KOHNO K, KOHYAMA J, NAMIHIRA M, KOMIYA S AND NAKASHIMA K. 2010. Neurons derived from transplanted neural stem cells restore disrupted neuronal circuitry in a mouse model of spinal cord injury. J Clin Invest 120: 3255-3266.

AIRES CCP, SOVERAL G, LUÍS PBM, TEN BRINK HJ, DE ALMEIDA IT, DURAN M, WANDERS RJA AND SILVA MFB. 2008. Pyruvate uptake is inhibited by valproic acid and metabolites in mitochondrial membranes. FEBS Letters 582: 3359-3366.

ARUN S, LIU L AND DONMEZ G. 2016. Mitochondrial Biology and Neurological Diseases. Curr Neuropharmacol 14: 143-154.

BACHMANN RF, WANG Y, YUAN P, ZHOU R, LI X, ALESCI S, DU J AND MANJI HK. 2009. Common effects of lithium and valproate on mitochondrial functions: protection against methamphetamine-induced mitochondrial damage. Int J Neuropsychopharmacol 12: 805-822.

BOHNERT M ET AL. 2012. Role of mitochondrial inner membrane organizing system in protein biogenesis of the mitochondrial outer membrane. Mol Biol of the Cell 23: 3948-3956.

BROMLEY RL, MAWER G, CLAYTON-SMITH J, BAKER GA AND LIVERPOOL AND MANCHESTER NEURODEVELOPMENT GROUP. 2008. Autism spectrum disorders following in utero exposure to antiepileptic drugs. Neurology 71: 1923-1924.

CASTRO-GAGO M, GONZÁLEZ-CONDE V, FERNÁNDEZ-SEARA MJ, RODRIGO-SÁEZ E, FERNÁNDEZ-CEBRIÁN S, ALONSO-MARTÍN A, CAMPOS Y, ARENAS J AND EIRÍS-PUÑAL J. 1999. Early mithocondrial encephalomyopathy due to complex IV deficiency consistent with alpers-huttenlocher syndrome. Report of two cases. Rev Neurol 29: 912-917.

CHATEAUVIEUX S, MORCEAU F, DICATO M AND DIEDERICH M. 2010. Molecular and therapeutic potential and toxicity of valproic acid. J Biomed Biotechnol 2010: 479364

CHEN X, WONG JYC, WONG P AND RADANY EH. 2011. Low-dose valproic acid enhances radiosensitivity of prostate cancer through acetylated p53-dependent modulation of mitochondrial membrane potential and apoptosis. Mol Cancer Res 9: 448-461.

CHRISTENSEN J, GRØNBORG TK, SØRENSEN MJ, SCHENDEL D, PARNER ET PEDERSEN LH AND VESTERGAARD M. 2013. Prenatal valproate exposure and risk of autism spectrum disorders and childhood autism. JAMA 309: 1696-1703.

COHEN MJ ET AL. 2011. Fetal antiepileptic drug exposure: motor, adaptive, and emotional/behavioral functioning at age 3 years. Epilepsy Behav 22: 240-246.

CUMMINGS C, STEWART M, STEVENSON M, MORROW J AND NELSON J. 2011. Neurodevelopment of children 
exposed in utero to lamotrigine, sodium valproate and carbamazepine. Arch Dis Childhood 96: 643-647.

DA COSTA RFM, KORMANN ML, GALINA A AND REHEN SK. 2015. Valproate Disturbs Morphology and Mitochondrial Membrane Potential in Human Neural Cells. App In Vitro Toxicol 1: 254-261.

DUAN X ET AL. 2007. Disrupted-In-Schizophrenia 1 regulates integration of newly generated neurons in the adult brain. Cell 130: 1146-1158.

FINSTERER J AND ZARROUK MAHJOUB S. 2012. Mitochondrial toxicity of antiepileptic drugs and their tolerability in mitochondrial disorders. Exp Op Drug Metabol Toxicol 8: 71-79.

FRAGA AM, SUKOYAN M, RAJAN P, BRAGA DP, IACONELLI A, FRANCO JG, BORGES E AND PEREIRA LV. 2011. Establishment of a Brazilian line of human embryonic stem cells in defined medium: implications for cell therapy in an ethnically diverse population. Cell Transplant 20: 431-440.

GAGE FH. 2000. Mammalian Neural Stem Cells. Science 287: 1433-1438.

HAKONEN AH, ISOHANNI P, RANTAMÄKI M, KÄLVIÄINEN R, NORDIN A, UUSIMAA J, PAETAU A, UDD B, PIHKO H AND WARTIOVAARA A. 2010. Mitochondrial recessive ataxia syndrome (MIRAS) and valproate toxicity. Duodecim 126: 155-159.

JENTINK J, LOANE MA, DOLK H, BARISIC I, GARNE E, MORRIS JK AND DE JONG-VAN DEN BERG LTW. 2010. Valproic acid monotherapy in pregnancy and major congenital malformations. New Eng J Med 362: 21852193.

JURATA LW, GALLAGHER P, LEMIRE AL, CHARLES V, BROCKMAN J, ILLINGWORTH EL AND ALTAR CA. 2006. Altered expression of hippocampal dentate granule neuron genes in a mouse model of human 22q11 deletion syndrome. Schizophr Res 88: 251-259.

KAMIYA A ET AL. 2005. A schizophrenia-associated mutation of DISC1 perturbs cerebral cortex development. Nat Cell Biol 7: 1167-1178.

KOMULAINEN T, LODGE T, HINTTALA R, BOLSZAK M, PIETILÄ M, KOIVUNEN P, HAKKOLA J, POULTON J, MORTEN K AND UUSIMAA J. 2015. Sodium valproate induces mitochondrial respiration dysfunction in HepG2 in vitro cell model. Toxicology 331: 47-56.

KRÄHENBÜHL S, BRANDNER S, KLEINLE S, LIECHTI S AND STRAUMANN D. 2000. Mitochondrial diseases represent a risk factor for valproate-induced fulminant liver failure. Liver 20: 346-348.

LAGACE DC, TIMOTHY O'BRIEN W, GURVICH N, NACHTIGAL MW AND KLEIN PS. 2004. Valproic acid: how it works. Or not. Clin Neurosci Res 4: 215-225.

LAI JS, ZHAO C, WARSH JJ AND LI PP. 2006. Cytoprotection by lithium and valproate varies between cell types and cellular stresses. Europ J Pharmacol 539: 18-26.

LEE SW, CLEMENSON GD AND GAGE FH. 2012. New neurons in an aged brain. Behav Brain Res 227: 497-507.
LEVYTSKYY RM, GERMANY EM AND KHALIMONCHUK O. 2016. Mitochondrial Quality Control Proteases in Neuronal Welfare. J Neuroimmune Pharmacol 11(4): 629-644.

LI R, LIU Y, CHEN N, ZHANG Y, SONG G AND ZHANG Z. 2016. Valproate Attenuates Nitroglycerin-Induced Trigeminovascular Activation by Preserving Mitochondrial Function in a Rat Model of Migraine. Int Med J Exp Clin Res 22: 3229-3237.

LI Z, OKAMOTO KI, HAYASHI Y AND SHENG M. 2004. The importance of dendritic mitochondria in the morphogenesis and plasticity of spines and synapses. Cell 119: 873-887.

LIN CM AND THAJEB P. 2007. Valproic acid aggravates epilepsy due to MELAS in a patient with an A3243G mutation of mitochondrial DNA. Metabol Brain Dis 22: 105-109.

LOPES C AND REGO AC. 2016. Revisiting Mitochondrial Function and Metabolism in Pluripotent Stem Cells: Where Do We Stand in Neurological Diseases? Mol Neurobiol 54: 1858-1873.

MANJI H, KATO T, DI PROSPERO N, NESS S, BEAL MF, KRAMS M AND CHEN G. 2012. Impaired mitochondrial function in psychiatric disorders. Nat Rev Neurosci 13: 293-307.

MANNELLA CA, LEDERER WJ AND JAFRI MS. 2013. The connection between inner membrane topology and mitochondrial function. J Mol Cell Cardiol 62: 51-57.

MAO Y ET AL. 2009. Disrupted in schizophrenia 1 regulates neuronal progenitor proliferation via modulation of GSK3beta/beta-catenin signaling. Cell 136: 1017-1031.

MATTSON MP, GLEICHMANN M AND CHENG A. 2008. Mitochondria in neuroplasticity and neurological disorders. Neuron 60: 748-746.

MAWHINNEY E ET AL. 2012. Valproate and the risk for congenital malformations: Is formulation and dosage regime important? Seizure 21: 215-218.

MEADOR K, REYNOLDS MW, CREAN S, FAHRBACH K AND PROBST C. 2008. Pregnancy outcomes in women with epilepsy: a systematic review and meta-analysis of published pregnancy registries and cohorts. Epilepsy Res 81: 1-13.

MEADOR KJ ET AL. 2009a. Cognitive function at 3 years of age after fetal exposure to antiepileptic drugs. N Eng J Med 360: 1597-1605.

MEADOR KJ ET AL. 2009b. Antiepileptic drug use in women of childbearing age. Epilepsy Behav 15: 339-343.

MEADOR KJ ET AL. 2013. Fetal antiepileptic drug exposure and cognitive outcomes at age 6 years (NEAD study): a prospective observational study. Lancet Neurol 12: 244252.

MERTENS J, MARCHETTO MC, BARDY C AND GAGE FH. 2016. Evaluating cell reprogramming, differentiation and conversion technologies in neuroscience. Nature Reviews. Neuroscience 17: 424-437. 
NANAU RM AND NEUMAN MG. 2013. Adverse drug reactions induced by valproic acid. Clin Biochem 46: 1323-1338.

PARK YU, JEONG J, LEE H, MUN JY, KIM JH, LEE JS, NGUYEN MD, HAN SS, SUH PG AND PARK SK. 2010. Disrupted-in-schizophrenia 1 (DISC1) plays essential roles in mitochondria in collaboration with Mitofilin. Proc Natl Acad Sci USA 107: 17785-17790.

PONCHAUT S, VAN HOOF F AND VEITCH K. 1992. Cytochrome aa3 depletion is the cause of the deficient mitochondrial respiration induced by chronic valproate administration. Biochem Pharmacol 43: 644-647.

PRAJUMWONGS P, WEERANANTANAPAN O, JAROONWITCHAWAN T AND NOISA P. 2016. Human Embryonic Stem Cells: A Model for the Study of Neural Development and Neurological Diseases. Stem Cells Int 2016: 2958210.

QING H ET AL. 2008. Valproic acid inhibits Abeta production, neuritic plaque formation, and behavioral deficits in Alzheimer's disease mouse models. J Exp Med 205: 27812789.

ROBICSEK O, KARRY R, PETIT I, SALMAN-KESNER N, MÜLLER FJ, KLEIN E, ABERDAM D AND BENSHACHAR D. 2013. Abnormal neuronal differentiation and mitochondrial dysfunction in hair follicle-derived induced pluripotent stem cells of schizophrenia patients. Mol Psy 18: 1067-1076.

ROSSIGNOL DA AND FRYE RE. 2012. Mitochondrial dysfunction in autism spectrum disorders: a systematic review and meta-analysis. Mol Psy 17: 290-314.

ROULLET FI, LAI JKY AND FOSTER JA. 2013. In utero exposure to valproic acid and autism--a current review of clinical and animal studies. Neurotoxicol Teratol 36: 47-56.

RUMBACH L, MUTET C, CREMEL G, MARESCAUX CA, MICHELETTI G, WARTER JM AND WAKSMAN A. 1986. Effects of sodium valproate on mitochondrial membranes: electron paramagnetic resonance and transmembrane protein movement studies. Mol Pharmacol 30: 270-273.

SENDROWSK K, SOBANIEC W, SOBANIEC P AND SOBANIEC-LOTOWSKA ME. 2013. Ultrastructural study of hippocampal cortex neurons in an experimental model of valproate encephalopathy. Folia Histochem Cytobiol 51: 31-37.
SGOBIO C ET AL. 2010. Hippocampal synaptic plasticity, memory, and epilepsy: effects of long-term valproic acid treatment. Biol Psy 67: 567-574.

SILVA MFB, AIRES CCP, LUIS PBM, RUITER JPN, IJLST L, DURAN M, WANDERS RJ AND TAVARES DE ALMEIDA I. 2008. Valproic acid metabolism and its effects on mitochondrial fatty acid oxidation: a review. J Inherit Metab Dis 31: 205-216.

SUI L AND CHEN M. 2012. Prenatal exposure to valproic acid enhances synaptic plasticity in the medial prefrontal cortex and fear memories. Brain Res Bull 87: 556-563.

TAIT SWG AND GREEN DR. 2012. Mitochondria and cell signalling. J Cell Sci 125: 807-815.

THOMAS SV, AJAYKUMAR B, SINDHU K, NAIR MKC, GEORGE B AND SARMA PS. 2008. Motor and mental development of infants exposed to antiepileptic drugs in utero. Epilepsy Behav 13: 229-236.

WIDE K, WINBLADH B AND KÄLLÉN B. 2007. Major malformations in infants exposed to antiepileptic drugs in utero, with emphasis on carbamazepine and valproic acid: a nation-wide, population-based register study. Acta Paediatr 93: 174-176.

WOODS DC. 2017. Mitochondrial Heterogeneity: Evaluating Mitochondrial Subpopulation Dynamics in Stem Cells. Stem Cells Int 2017: 7068567.

YOCHUM CL, DOWLING P, REUHL KR, WAGNER GC AND MING X. 2008. VPA-induced apoptosis and behavioral deficits in neonatal mice. Brain Res 1203: 126132.

ZERBES RM ET AL. 2012. Role of MINOS in mitochondrial membrane architecture: cristae morphology and outer membrane interactions differentially depend on mitofilin domains. J Mol Biol 422: 183-191.

ZHANG Y, WU JY, WENG LH, LI XX, YU LJ AND XU Y. 2017. Valproic acid protects against MPP(+)-mediated neurotoxicity in SH-SY5Y Cells through autophagy. Neurosci Let 638: 60-68.

ZHVANIA MG, KSOVRELI M, JAPARIDZE NJ AND LORDKIPANIDZE TG. 2015. Ultrastructural changes to rat hippocampus in pentylenetetrazol- and kainic acid-induced status epilepticus: A study using electron microscopy. Micron 74: 22-29. 